\title{
Investment Analysis of PDD
}

\author{
Yishan Huang ${ }^{1, *, a, \dagger}$, Guanhua Xu ${ }^{2, *, b, \dagger}$, Xikai Yang ${ }^{3,{ }^{*}, \mathrm{c}, \uparrow}$ \\ ${ }^{1}$ University of California, Santa Barbara. \\ ${ }^{2}$ Zhongnan University of Economics and Law, Wuhan. \\ ${ }^{3}$ University of Toronto, Mississauga. \\ "Corresponding author.Email:ayishan@ucsb.edu,b201821060315@stu.zuel.edu.cn,cxikai.yang@mail.utoronto.ca \\ ${ }^{\dagger}$ These authors contributed equally.
}

\begin{abstract}
The research aims to determine the possibility of investing in PDD by evaluating the trend of financial performance over the last five years. The evaluation of the total revenues and the profitability will show the investors the possibility to gain investment returns. However, other factors such as the investment prospects and strategies will show the company's efforts to promote performance, such as expanding the efficiency of the logistics network and creating new e-commerce platforms and concepts. Such investment output will guide the investors in making investment decisions on PDD. In specific, different financial models will be utilized, such as the POCD framework, SWOT analysis, and PEST analysis, to further discuss the prospects of PDD. Overall, PDD grows rapidly in the e-commerce market, providing it with mass opportunities based on the POCD and SWOT analysis. The PEST analysis further reinforces the growth as consumers commonly use Alipay along with PDD. Eventually, all these aspects make PDD a positive firm to invest in.
\end{abstract}

Keywords: PDD; PEST analysis; POCD analysis; SWOT analysis; financial analysis; PE analysis.

\section{INTRODUCTION}

The most important meaning of investing in a startup can be divided into two parts.

The first and the most important one, the essence of investing, is allocating money and resources, which means that it makes any penny meaningful and contributes to the most potential idea. Besides that, the investors also pursue as higher as possible return to make their assets more valuable. Based on these two reasons, to determine whether a startup is valuable to invest in, we need to use some model to evaluate the worth of an idea. That includes its management team, policy support, target customers, competitors, core advantages, etc., as well as the possible return for the investment, including return rate, ownership dilution, and exit point. To be specific, in 208, the investment amount of Alibaba Group is 180 billion, returning for 25.4 billion in one year; and Tencent invests 90 billion, bring 23.2 billion return, which occupies for one-third of its total revenue. The investment amount of Alibaba and Tencent keeps growing from year to year. They acquired much successful e-commerce and held a large portion of ownership in a different industry.
The company we are evaluating is PDD, one of the most potential companies these years. PDD has a unique business model and is oriented by price, signifying sharing, exploring, and purchasing. The experience is built by combining aspects of online and offline shopping. Such a unique business makes PDD reliable for the common person because of its power of relatability. The platform is built, run, influenced, and validated for and by people like you and me, achieving successful social commerce. In addition to its business model, the PDD supply chain is directly connected to actual market needs, ensuring the diversity of products and the lowest price. So far, PDD has gone public and received Alibaba, Tencent, and more than ten big venture capital financing; the company's valuation still remains the growth tendency.

The paper has referenced an overall of 10 pieces of literature. Firstly, a perspective falls into the nature of investors that relates to the impact of stock volatility in the investment decision. This would help evaluate the financial reports of PDD [1]. Then, Dai introduces the techniques to understand the prospects of stock market volatility; according to his perspective, PDD is statistically proven to be highly volatile and less risky [2]. Other than that, tools and techniques are given to 
managers, executives, and entrepreneurs to analyze markets and businesses effectively. This corresponds with how "people" work from the POCD framework [3]. PDD achieved significant growth in its return in recent years. This article evidently provides how PDD makes mass return precisely [4]. Furthermore, appropriate positioning and business models are utilized by PDD, and this greatly impacts the part of "opportunity" from both the POCD framework and the SWOT analysis [5]. PDD has to optimize its revenue in management; according to the online algorithms' approach, PDD will not require demand forecasts or a risk-neutrality assumption. In this way, PDD maintains its best performance [6]. Additionally, the paper utilized the PEST analysis to conduct research and identify all four elements towards businesses [7]. The SWOT analysis helps to audit marketing strategies, but it lacks a sense of experience. With the five-point approach presented by the author, focusing on the marketing planning process would better help evaluate PDD [8]. Moreover, from the perspective of consumer psychology, PDD expands its vision and targets correctly. This helps the firm achieve benefits from group pooling [9]. Lastly, Zhixi comes up with different applications to research consumer behaviors and, by taking PDD as an example, how would people react when PDD implement their strategies [10].

The remainder of the paper is organized as follows: Section 2 to 4 presents some analysis frameworks, including the PEST, POCD, and SWOT analysis. Section 5 introduces the financial analysis of PDD. It includes the analysis of stock price/revenue analysis/financial history. Section 6 uses PE analysis to assess the investment prospects. In the end, Section 7 draw to our conclusion and personal thinking for the PDD investment.

The body text starts with a standard first-level heading like INTRODUCTION or any other heading suitable to the content and context. First-level headings are in all caps. Copy the content and replace it with other first-level headings in the remaining text. Reference citations should be within square brackets [1]. Headings should always be followed by text.

This template, modified in MS Word 2007 and saved as a "Word 97-2003 Document" for the PC, provides authors with most of the formatting specifications needed for preparing electronic versions of their papers. All standard paper components have been specified for three reasons: (1) ease of use when formatting individual papers, (2) automatic compliance to electronic requirements that facilitate the concurrent or later production of electronic products, and (3) conformity of style throughout the conference proceedings.

\section{PEST ANALYSIS}

PEST analysis refers to the macro-environment analysis, The $\mathrm{P}$ refers to politics, E refers to economy, $\mathrm{S}$ refers to society, $\mathrm{T}$ refers to technology. When analyzing the background of an enterprise group, it is usually through these four factors to analyze the situation faced by the enterprise group. The main contents of the economy include the level of economic development, scale, growth rate, government revenue and expenditure, inflation rate, etc. Political aspects include political system, government policy, national industrial policy, relevant laws and regulations, etc. Social aspects include population, values, and moral standards. In terms of technology, there are breakthroughs in high and new technology, process technology, and basic research.

\subsection{Analysis of Political Environment}

Since the 1990s, with the rapid development of Internet technology, the number of Chinese Internet users has also increased rapidly. It is an important principle for the development of China's Internet industry to build, network, and use the network according to law, and it is also a joint effort of all countries in the world Law. In recent years, China attaches great importance to the construction of Internet laws and regulations, standardizing

Chinese Internet order, and the relating the legal construction. The basic work of setting up and filing websites is progressing steadily. The Standing Committee of the National People's Congress on Internet security has promulgated and implemented the "The Eleventh Five Year Plan for the development of ecommerce", "the plan for the adjustment and revitalization of the electronic information industry" and "electronic signature" Law of the people's Republic of China and guidelines for electronic payment provide strong legal protection for regulating online transactions. It can be seen that the state pays more and more attention to the development of e-commerce, and the relevant regulatory work is also gradually launched and implemented. These new changes are good for politics. The government's standardized guidance and promotion of e-commerce in the future is more conducive to the long-term development of the e-commerce market.

\subsection{Economic Environment Analysis}

The scale of Internet users continues to grow rapidly. The huge number of Internet users has brought huge business opportunities to develop the Internet industry and broad market space. The operating rate of ecommerce has been further improved, and the ecommerce platform has continued to deepen its development in the industry. The rapid growth of the online shopping market has become a huge driving 
force for consumption and economic growth. And with China with the increasing number of $\mathrm{C} 2 \mathrm{C} / \mathrm{B} 2 \mathrm{C}$ market entrants and a large amount of capital investment, the competition will be more intense. The competition will produce two sides, as a result, on the one hand, some C2C / B2C websites gradually improve their own governance and services, it provides a good trading environment for both sides of the transaction, accumulates a huge customer base, and forms an obvious network economic effect. Some small websites can't bear the burden and gradually launch the market, which will help the market to mature; On the other hand. It has attracted great attention from all walks of life, cultivated people's habit of online trading, deepened their participation, and brought great challenges and development of the C2C / B2C market. All of these will bring PDD to a good development path.

\subsection{Social Environment Analysis}

Nowadays, e-commerce activities have been involved in almost all commercial fields, and online shopping has penetrated our daily life, which undoubtedly brings more and better development opportunities to PDD. In recent years, with the rapid growth of Internet users, the scale of online shopping potential users is also expanding, promoting the development of China's C2C / B2C e-commerce market.

On the other hand, online shopping is a change of usage and consumption habits. For users who are used to traditional contact and shopping guide shopping, many factors drive the first online shopping, among which price is the most important one. In addition, problems in any link of the whole process of ultimate purchase will lead to the loss of users. The related social supporting services such as logistics and payment also determine whether users are willing to accept online shopping. With the continuous improvement of related social supporting services such as logistics and payment, online shopping is becoming more and more popular, and the number of online shopping is increasing.

\subsection{Technical Environment Analysis}

Since the 1990s, the rapid development of network technology, especially the popularity of classified search engines, the improvement of interactive community platform technology, and the development of instant chat tools, has played a certain role in promoting the development of online shopping platform technology, especially the invention and promotion of electronic payment. Third-party payment platform technology (Alipay) and digital certificate security authentication. Other new technologies are emerging and constantly improving, which have made the online shopping technology platform constantly updated, the interface is more friendly, the function is more powerful, and the interaction and security have also been greatly strengthened.

\section{POCD ANALYSIS}

The POCD framework analyzes a company's value through four aspects: People, Opportunity, Context, and Deal. Specifically, by managing the group or providing resources for the venture, we can know that to what degree these people have the right experience and skills. By opportunity, we evaluate any activity requiring the investment of scarce resources in hopes of future return. By context, we analyzed that to what degree the macroeconomic market influence the company, including inflation rate, government policy, consumer sensitivity, and its competitors, as well as the reaction ability of the people. By deal part, we search for the financing history of a company along with its changing of valuation and make some assumption of exit path and profit-making strategies as venture capital. These four aspects deeply influence the outcome of investment and how things are going in the next stage by our decision.

\subsection{People}

As a venture capital investor, PDD is a good startup. It can potentially grow and succeed because of the current management team and experienced people employed in the company. The Chairman of the Board and Chief Executive Officer is Lei Chen, who is graduated from Tsinghua University with a computer science Bachelor's degree and a master's degree from Wisconsin-Madison University. $\mathrm{He}$ has a strong background in computer science, and that deep comprehension contributes to the field that he joined in and his company. Besides that, other partners all have high education and experience from their expertise fields such as Skadden、Arps、Slate、Meagher\&Flom LLP, Baidu, etc. Higher education and experience ensure their ability to learn and their professional skills, critical in managing a company. However, the diversity of team members is a small concern of some investors, as most of the key numbers have computer science education backgrounds.

\subsection{Opportunity}

One opportunity of PDD is to catch up with the growth of e-commerce and flow, as the total market for the e-commerce product is rapidly growing. Although the industry is attractive and strictly competitive, PDD has its advantages and finally wins the game. It was founded in 2015 as PDD, buying fruits in bulk from farmers and selling them directly to consumers using online channels. During this period, PDD accumulates large users before the transition. 
The main customer of PDD is large, nearly including everyone in the world. The main advantage is price, as we can see that PDD has the lowest price compared with other e-commerce platform. Since the product on PDD mainly consists of daily items, the sensitivity of customers to the price is relatively high, leading to the larger users of PDD. Apart from these, PDD is onto many more projects to ensure it captures a heavy chunk of market share, advertising its products through social connections. Every user can get a lower price when they share PDD with their friends; briefly to say, the more you share, the lower price you get. In that case, such Duo Duo Crush game develops its advantages of price and, at the same time to improves its total sales.

\subsection{Context}

PDD caught up with the fastest growth of ecommerce at its early stage and accumulated most customers with their acute insight. Because they caught up at the right time of e-commerce growth, PDD entered its primitive accumulation of capital and became more famous in its industry. Besides that, the advertising strategy of PDD is nearly cost-free and expands its market by sharing, resulting in higher customer stickiness and reliance.

More importantly, PDD has lower sensitivity to the overall economic context. As the form of PDD is mainly by customers sharing, the e-commerce system would hardly be impacted by interest rate, inflation, exchange rate, and tax policy, as it has various products.

However, although PDD has the lowest price, the quality of the product cannot be ensured. Since customers have high sensitivity to price, they have a higher reliance on PDD. In contrast, as they continue getting low-quality products, the reliance would be lower since everyone cares.

\subsection{Deal}

Before the IPO financing round, PDD receives a total of 3 billion dollars, and after IPO, the valuation of PDD is up to 30 billion dollars. In 2015.8, PDD received millions of dollars from individual investors in series A financing round. In the 2016.7 series B round, PDD obtained a totally of 0.11 billion dollars from several venture capital; and in the 2017.1 series C round, it received billions of dollars from Sequoia venture capital; and finally, in the 2018.4 series D round, Tencent joins in the game and invested 3 billion dollars. The growth tendency of PDD still remains in the future, and the price-oriented model of PDD might need to improve and expand its advantages into more fields. Since Tencent group and other big companies are in this game, so we don't know whether PDD can be acquired in the future.

\section{SWOT ANALYSIS}

The competition of the whole e-commerce industry is becoming increasingly fierce, so it is of great significance to determine the competitive strategy suitable for the long-term development of the platform itself. This section first analyzes the strategic environment of PDD with the SWOT analysis method, then expounds on the formulation of PDD's competitive strategy, and finally analyzes PDD's competitive advantage with a strategic map.

Due to the rapid development and wide application of the Internet, e-commerce is rising. The emergence of e-commerce has changed our way of life to a certain extent. Among many e-commerce platforms, PDD, as a rising star, develops rapidly with its unique marketing methods and competitive strategies. PDD was launched in September 2015. Users can compete with their relatives and friends to buy high-quality products at a lower price. This is also the innovation and advantage of PDD. PDD platform products have covered many categories, including clothing, food, 3C, home appliances, home furnishings, etc., to meet the growing diversified needs of consumers. PDD will be listed in July 2018, which means it has greater development potential. Therefore, the research on its competitive strategy in this paper will become more meaningful.

PDD is a third-party social e-commerce platform, which creates a unique way of online shopping. That is, users can form a pintuan, a new online shopping mode. For example, the original product sold for 100 yuan, but we only need to invite another friend to buy it with us. We only need to spend 90 yuan to buy this product) with their relatives and friends through sharing. Thus, pintuan can gather more people's strength to buy better products at a lower price.

\subsection{Strength}

Huang Zheng, the founder of PDD, has mastered advanced foreign technology. He worked for Google in the United States and participated in the establishment of the Google China office. Huang Zheng has founded an e-commerce agent operation company and game company. His rich experience makes him familiar with the psychology of users and grasps the opportunity in time. In addition, the creativity of PDD's founding team helped PDD attract more investment. The most important thing is that PDD has grasped the gap in the third-tier cities and rural markets and realized the lowcost connection between the low-end supply chain and the low-end consumers through the way of PDD.

\subsection{Weakness}

First of all, PDD makes many people dissatisfied with the fact that counterfeit goods and counterfeit 
goods are everywhere on the platform. Although PDD will be more preferential than Taobao and Jingdong, the problem of the product itself will be a hard wound. Because of the improvement of living standards, people will pay more and more attention to the quality of products. Therefore, some users would be diverted by others e-commerce platforms in the future. Secondly, PDD now faces limited users in third-tier cities and rural markets. To achieve sustainable development, it must compete with other e-commerce platforms to seize the first and second-tier city markets

\subsection{Opportunities}

The state highly supports the development of rural ecommerce. In recent years, the development of rural ecommerce is not optimistic. With the support of policies, the development space of rural e-commerce will be further increased. In addition, the number of Internet users in China is increasing, and the proportion of people who choose to shop online in the total number of Internet users is also rising. After the Taobao upgrade, many low-end suppliers are out, but the low-end supply chain still exists, and the low-end consumers also exist. If PDD can turn these low-end suppliers into its own businesses, it can attract more users.

\subsection{Threats}

Taobao, Jingdong, and other e-commerce platforms are also constantly optimized, so PDD faces many strong competitors. In addition, PDD's pintuan mode may not last long because it wastes a lot of manpower and time cost. At the same time, most of PDD's pintuan products are fruits, cosmetics, and other daily necessities, because they are cheaper and easier to generate orders. In the end, there may be no one to cooperate with, and the relationship between relatives and friends may deteriorate.

\section{FINANCIAL ANALYSIS}

\subsection{Stock Price Analysis}

Based on the statistics from Yahoo Finance, the stock price of PDD from June 2020 to June 2021 is displayed in Table 1 below. Over the last years, the share of PDD increased by $56.57 \%$, which is more than the overall market average. Investors can expect higher returns based on huge returns over the next period. However, other companies and external factors might impact the stock returns, such as financial crisis and government intervention.
Table 1: Total Annual Stock of PDD

\begin{tabular}{ll}
\hline Start Price & $6 / 15 / 2020$ \\
77.67 & $6 / 14 / 2021$ \\
Ending Price & \\
121.61 & \\
Change & \\
43.94 & \\
Total \% stock return & \\
$56.57 \%$ & \\
\hline
\end{tabular}

Source: (Yahoo Finance, n.d.).

Figure 1 shows that the average daily stock price of PDD has been increasing consistently over time. However, in the last 3 months, the share price has slumped slightly. Despite the short-term decline in share price, it remains an attractive investment for investors.

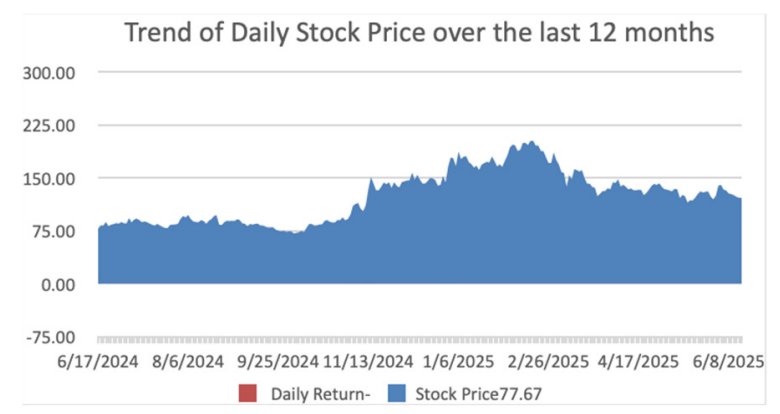

Fig. 1 Trend of Daily Stock Price over the last 12 Months

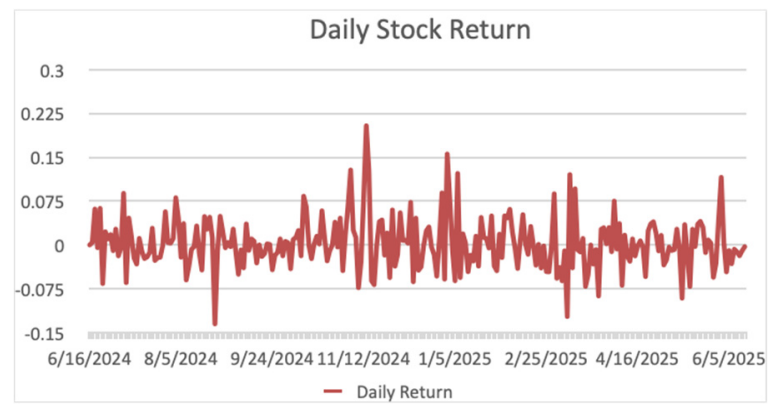

Fig.2 Average Daily Stock Return

The volatility of the stock is measured by the determination of the standard deviation, which measures the dispersion of the share price over the 12 months. A higher standard deviation implies that the company's share price is relatively unstable, and it might lead to increased losses for the investors [1]. However, a lower standard deviation implies the volatility is lower, and thus, there are no risks for sudden adverse changes in share price [1]. Based on the computation, the standard deviation of the share price of PDD over the last 12 months is 0.04447 . The lower standard deviation implies that investing in PDD shares is relatively less risky because the volatility is lower.

\subsection{Revenue Analysis}

Over the last five years, the total revenues of PDD have been growing significantly. In 2016, the company's 
total revenues were 505 million and increased to more than 50,000 million in 2020, indicating the positive growth and expansion of the company.

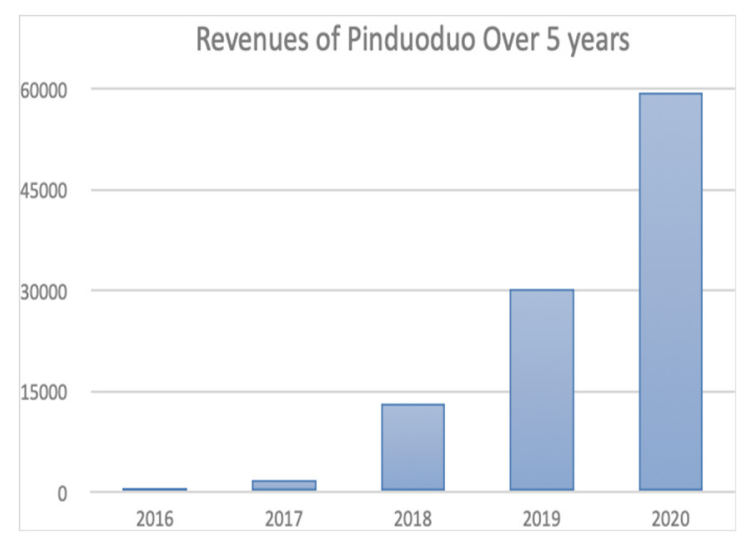

Fig.3 Revenues of PDD over 5 Years

\subsection{Financial History}

Based on the IPO share price (Initial public offering), the valuation of PDD is \$24 billion based on the company's potential. The company was registered in the NASDAQ (National Association of Securities Dealers Automated Quotations) under the ticker PDD with an opening share price of $\$ 19.00$ per share. During the IPO, the company raised $\$ 1.6$ billion that are being used to implement its investment projects and expand its operations effectively.
The investment prospects and goals indicate some of the programs PDD is adopting to improve the capacity to make significant revenues and improve their returns effectively.

\section{P/E ANALYSIS}

$\mathrm{P} / \mathrm{E}$ ratio refers to the Price-to-Earnings Ratio, which is one of the most widely used metrics for investors in the stock market; while it can still be utilized to analyze the company's value. P/E ratio reveals how a stock's valuation compares to its industry group or a benchmark like the S\&P 500 index.

As we can see from the table below, the $\mathrm{P} / \mathrm{E}$ ratio of PDD has a growth tendency, saying that there would be a dramatically increasing rate in these years. Sometimes, the $\mathrm{P} / \mathrm{E}$ ratio influences a company's valuation, as it reflects the performance in the secondary market (especially refers to the stock market). From Table 3 and Table 4, we observe the $\mathrm{P} / \mathrm{E}$ ratio from negative to positive. Regardless that PDD is a new company in the second market, the future earning of PDD would be growing and can be seen as a potential "unicorn" in its industry. We predict that in 2023, the fee for PDD's price would be paid back to investors in 37.75 years. We also find that the $\mathrm{P} / \mathrm{E}$ growth rate is very high, increasing to $236.3 \%$ in 2022 .

Table 2: Financial goals and prospects of PDD

\begin{tabular}{cc}
\hline $\begin{array}{c}\text { Financial Goals } \\
\text { and Prospects }\end{array}$ & Information \\
$\begin{array}{c}\text { To create a new e-commerce concept } \\
\text { and experience. }\end{array}$ & $\begin{array}{c}\text { The establishment and promotion of new e-commerce } \\
\text { concepts and experiences led to the evolution of a wide range of pin } \\
\text { formats that allow users to make online purchases growing } \\
\text { revenues. }\end{array}$ \\
$\begin{array}{c}\text { Integration of cyberspace and } \\
\text { physical space. }\end{array}$ & $\begin{array}{c}\text { The prospect would promote the network of intelligence agents, } \\
\text { which improves social interactions and the growth of online } \\
\text { revenues. }\end{array}$ \\
Improving logistics capability. & $\begin{array}{r}\text { PDD Increase has created well-penetrated and effective logistic } \\
\text { chains to prevent damage to the perishable and fresh produce } \\
\text { obtained from the local farmers. }\end{array}$ \\
\end{tabular}

Table 3. PDD Price/Earning Ratio

\begin{tabular}{ll}
\hline 2020 Actual & -138.7 \\
\hline 2021 Estimates & -255.2 \\
2022 Estimates & 236.3 \\
2023 Estimates & 39.75
\end{tabular}

Table 4. PDD Forecast $\mathrm{P} / \mathrm{E}$ Growth Rate

\begin{tabular}{ll}
\hline Growth 2021 & 46.2 \\
\hline Growth 2022 & 208.08 \\
P/E 2021 & -255.2 \\
P/E 2022 & 236.3
\end{tabular}




\section{CONCLUSION}

PDD is a unicorn company, which operates an ecommerce site in China. The company offers a wide range of products such as bags, shoes, consumer electronics, and cosmetics. The assessment of the return and volatility of PDD will inform the investors on whether to invest in the stock depending on the historical share performance.

Through the company's macro analysis and data research, we can find that PDD has developed rapidly in recent years, and its high rate of return on investment has brought a lot of income to shareholders. Therefore, from the perspective of long-term investment in the capital market, PDD is a company worthy of investment, especially in recent years. However, it can not rule out the corresponding risks, so how to invest and when to invest. The amount of investment will still have a significant impact on the final investment income.

This paper makes a detailed study of PDD company and its stock price, but lacks the analysis of the corresponding competitors in the market and the quantitative analysis under the econometric model, so it can not rule out the analysis error caused by the fluctuation of data and deviation from the actual value. Besides, the stock market is changing rapidly, and the past performance can not fully represent the future development level. Therefore, the analysis of PDD's future market share and the evaluation of the company's profits need to be combined with more factors and more practical opinions. As for the detailed gain and loss of this paper in the future, we are willing to leave it to the readers to make a professional judgment with an open mind.

\section{REFERENCES}

[1]. Che, L. (2018). Investor types and stock return volatility. Journal of Empirical Finance, 47, 139161.

[2]. Dai, Z., Zhou, H., Wen, F., \& He, S. (2020). Efficient predictability of stock return volatility: The role of stock market implied volatility. The North American Journal of Economics and Finance, $52,101-174$.

[3]. Helfert, E. . (2001). Financial analysis : tools and techniques : a guide for managers. McGraw-Hill.

[4]. Hughes, A. . (2019). Pinduoduo makes quick return. International Financing Review(2270), 69-69.

[5]. Jian-Yue, J. I. , Lin, Z. C. , Yi-Fei, L. I. , \& Economics, S. O. . (2019). Research on pinduoduo's business model under the background of generalized virtual economy. Research on the Generalized Virtual Economy.
[6]. Michael, O., Ball, Maurice, \& Queyranne. (2009). Toward robust revenue management: competitive analysis of online booking. Operations Research.

[7]. Peng, G. C. , \& Nunes, M. B. . (2007). Using PEST Analysis as a Tool for Refining and Focusing Contexts for Information Systems Research. 6th European Conference on Research Methodology for Business and Management Studies.

[8]. Piercy, N. , \& Giles, W. . (1989). Making swot analysis work. Marketing Intelligence \& Planning, $7(5 / 6), 5-7$.

[9]. Y Bie. (2020). Consumer Psychology Analysis of Sinking Users Based on E-Commerce Platform Taking Pinduoduo as an Example. IEEE.

[10]. Zhou, Z. . (2021). Application of Customer Analysis Methods to Online Business Services Take Pinduoduo for Example. 6th International Conference on Financial Innovation and Economic Development (ICFIED 2021). 